\title{
Tensile Properties of 3D-printed Continuous-Fiber-Reinforced Plastics
}

\author{
NICOLAE FLORIN COFARU ${ }^{1}$, ADRIAN PASCU ${ }^{2 *}$, MIHAELA OLEKSIK ${ }^{2}$, RADU PETRUSE ${ }^{1}$ \\ ${ }^{1}$ Lucian Blaga University, Faculty of Engineering, Industrial Engineering and Management Department, 10 Victoriei Blvd., \\ 550024, Sibiu, Romania \\ ${ }^{2}$ Lucian Blaga University, Faculty of Engineering, Machines and Industrial Equipment's Department, 10 Victoriei Blvd, \\ 550024, Sibiu, Romania
}

\begin{abstract}
Obtaining parts made of composite materials through 3D Printing Additive manufacturing have fully proved their usefulness due to several advantages such as: the possibility to directly create complex shapes without going through the classic process of transforming the semi-finished products into finished parts through technologies that consume resources and energy and are unfriendly to the environment. The main disadvantage of the parts made by $3 D$ Printing technologies is that they are less resistant from a mechanical point of view. This can be solved by the development of $3 D$ printers capable of printing composite parts consisting of a plastic matrix reinforced with continuous fibers. This research focuses on studying 4 types of $3 D$-printed Continuous-Fiber-Reinforced Plastics (CFRP) from the point of view of their mechanical properties: Onyx - rigid nylon in which micro carbon fibers are inserted and Onyx reinforced with carbon, glass or Kevlar fiber. Standardized specimens were made for the uniaxial tensile test and the experimental program was designed evaluating: the Elastic modulus [GPa], the Maximum Tensile stress [MPa], the Tensile strain at maximum Tensile stress [ $\mathrm{mm} / \mathrm{mm}$ ]. The principal strains were also determined, using the digital image technique made using the Aramis system from GOM. The experimental tests confirm that these new materials will be serious candidates to be used in engineering applications in various fields.
\end{abstract}

Keywords: CFRP, 3D Printing, Fused Filament Fabrication (FFF), mechanical characteristics, Continuous Filament Fabrication (CFF)

\section{Introduction}

Recently, the intelligent use of energy resources, the responsible management of raw materials and the ever-growing emphasis on products and processes that take into account the impact of industries on the environment have contributed to the emergence and development of new materials and nontraditional technologies.

Such new materials are composite materials, whose high capacity for adaptability has encouraged a proliferation of the fields [1] in which they are employed. Some examples include bioengineering and biomechanics, aeronautical industry, machine-building industry, naval constructions and civil and industrial constructions.

These materials have properties such as a very good reproducibility, a higher strength-weight ratio, low specific mass, absence of corrosion, resistance to shock, traction and fatigue, low coefficient of thermal dilatation, chemical stability, abrasion resistance, high durability and reliability [2]. It is on account of these properties that such materials are favored over classical ones in many engineering applications.

As is widely known [3], composite materials are defined as a combination, at a macroscopical scale, of two or more materials from which new material, with better properties than the initial components, is manufactured. A subcategory of these is the composite materials of a plastic matrix reinforced with different fibers. The reinforcement of plastic materials can, in theory, be accomplished by using short discontinuous fibers or long and continuous fibers [4].

*email: adrian.pascu@ulbsibiu.ro 
Two technologies frequently used for obtaining parts from such materials are Fused Filament Fabrication (FFF) or Continuous Filament Fabrication (CFF), two technologies which are part of what is known as Additive manufacturing [5, 6-8]. These technologies, subsumed under the generic umbrella term "3D Printing," have in common the manufacturing of parts through the deposition of successive layers of material onto a 3D model obtained through a CAD software and present clear advantages such as: use of material coefficient of $100 \%$, the possibility to create complex forms which are hard to accomplish through other technological processes, direct manufacturing of the finite product without having to first create a blank and then proceed to classical cutting processes. Despite their many advantages, these technologies came with an important downside, which consisted of the fact that the materials commonly used for 3D printing, such as Nylon, Acrylonitrile Butadiene Styrene (ABS) or Polylactic Acid (PLA) generated parts with modest mechanical characteristics, no chemical resistance and insufficient durability for industrial applications. [9]. This disadvantage has disappeared in the last five years with the emergence of 3D printers [10] offering reinforcement opportunities, hence the manufacturing of more robust parts with mechanical characteristics similar to those of metallic materials.

In this context, a feasible strategy to enhance the mechanical characteristics of composites is that of using a Short Fiber-Reinforced Composite [11]. These are obtained by using, in 3D printing, a thermoplastic polymer filament, into which short carbon or glass fibers and basalt fibers [12] are inserted. Previous studies [10] show that the reinforcement of composites with Short Fiber can increase tensile strength and Young's modulus by $25-30 \%$ in the case of carbon and of up to 30-40\% for basalt $[5,13,14]$.

The reinforcement of the composite with long continuous fibers is the second strategy, which consists of using two materials during the 3D printing process, i.e., continuous reinforcing fibers and a matrix polymer, which are put together during the printing process. The 3D Printing of Continuous FiberReinforced Composite $[15,16]$ has caught the attention of researchers in the field due to its high potential for enhancing the mechanical characteristics of composite materials. For example, in accordance with $[4,17]$, PLA reinforcement with CCF (continuous carbon fiber) produces spectacular increases (180$200 \%$ ) in tensile strength.

Our paper aligns with past related research, while aiming to further study the mechanical characteristics of composite materials reinforced with short or discontinuous fibers, but also with long or continuous fibers.

\section{Materials and methods}

The materials used in the study are composite materials reinforced with short carbon fibers. These materials will also be tested in a scenario where supplementary continuous carbon, Kevlar and glass fibers reinforcement is provided.

\subsection{Materials}

As previously mentioned, reinforced composite materials are obtained from the addition of reinforcement fibers to the base matrix. For the base matrix, Onyx will be used. Onyx is a material created by the Markforged ${ }^{\circledR}$ company (Watertown, MA, USA) [10]. The base mass consists of rigid nylon in which micro carbon fibers are inserted. The materials are strong, stiff, with high dimensional stability, good heat resistance and an aesthetically pleasing exterior after printing [10]. Moreover, the material is chemically resistant and can be reinforced with continuous fiber. The manufacturer of the material guarantees that the parts printed from Onyx are 1.4 times stronger and stiffer than ABS, for example. Its mechanical characteristics are presented in Table 1.

Table 1. Onyx - Mechanical characteristic $[2,10]$

\begin{tabular}{|c|c|}
\hline Tensile Modulus (GPa) & 2.4 \\
\hline Tensile Stress at Yield (MPa & 40 \\
\hline Tensile Stress at Break (MPa & 37 \\
\hline
\end{tabular}




\begin{tabular}{|c|c|}
\hline Tensile Strain at Break $(\%$ & 25 \\
\hline Flexural Strength (MPa) & 71 \\
\hline Flexural Modulus $(\mathrm{GPa})$ & 3.0 \\
\hline Heat Deflection Temp $\left({ }^{\circ} \mathrm{C}\right)$ & 145 \\
\hline Density $\left(\mathrm{g} / \mathrm{cm}^{3}\right)$ & 1.2 \\
\hline
\end{tabular}

The fibers with which Onyx will be reinforced are: carbon fiber, Kevlar fiber and glass fiber. The carbon fiber is characterized as an ultra-high-strength continuous fiber and when inserted in a Composite Base material like Onyx, it can yield parts as strong as 6061-T6 Aluminum [2,10]. The most important characteristics of this fiber are its high strength-to-weight ratio and stiffness.

Kevlar is known for its toughness and energy absorption. By reinforcing Onyx with Kevlar, a composite material highly resistant to impact in repetitive loading scenarios will result $[2,10]$.

Glass fiber is a reinforcement fiber that, when inserted in a material such as Onyx, allows for the manufacturing of materials capable of yielding parts 10x stronger than ABS [10].

\subsection{Specimen preparation}

To determine how reinforcement composites influence the mechanical properties of 3D printed components, the specimens required for this experiment were manufactured in accordance with the ASTM D638-02a Standard Test Method for Tensile Properties of Plastics [18]. According to the previously mentioned standard, the suitable test specimen type for reinforced composites is the Type I specimen, whose dimensions were customized as shown in Figure 1.

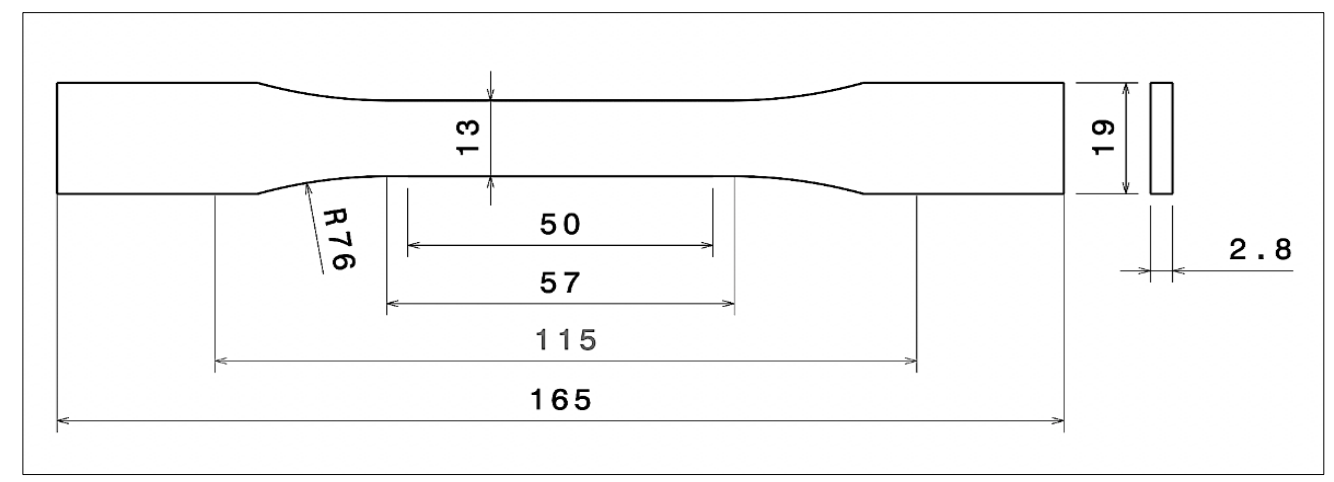

Figure 1. Specimențs dimmensions selected from ASTM D638-02a Type I [18]

For this experiment, there were used 4 different specimen compositions of which 3 contain one of the following reinforcement fibers: carbon fiber (CF), Kevlar fiber (K) or glass fiber (GF). Each reinforcement fiber type requires a specific layer thickness $(0.093 \mathrm{~mm} / \mathrm{layer}$ for GF and Kevlar and $0.11 \mathrm{~mm} /$ layer for CF). Since the reinforcement material is expected to have the highest influence on the mechanical properties of each specimen and to ensure that the same amount of reinforced layers are fitted into each specimen type and the infill material is kept to a minimum,, the width of the test specimens was set for $2.8 \mathrm{~mm}$, which is within the ASTM D638-02a dimensional tolerances. At this width, 14 reinforced layers were inserted in each specimen type as depicted in Figure 2. The other layers, which were not reinforced, were adjusted according to the 3D printer's manufacturer's recommendations of having a minimum of 4 top and bottom layers. The number of unreinforced layers varies depending on reinforcement type. However, they are always symmetrically distributed atop and below the specimen. 


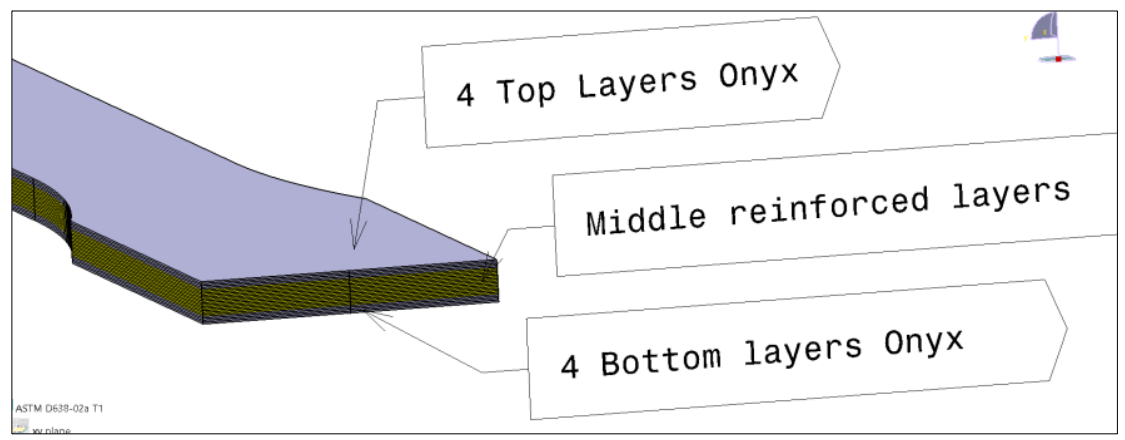

Figure 2. Reinforced specimen structure

The 3D printing technologies used to manufacture the specimens are Fused Filament Fabrication (FFF) for the parts without reinforcement and Continuous Filament Fabrication (CFF) for the reinforced specimens. Since plastic materials are influenced by the environment in which they are manufactured (e.g., humidity), all specimens were built on the same 3D printer in a controlled environment. Moreover, all materials were stored in the same room with controlled humidity and temperature. After all the specimens were manufactured, they were stored in a sealed bag to ensure that no environment-related changes affected them

The suitable 3D printer for this experiment is Mark Two from Markforged, which allows for printing reinforced parts using CFF printing technologies. Mark Two is specialized in 3D printing short fiberreinforced composite (Onyx material) via the FFF technology and long fiber-reinforced composites via CFF.

As for the manufacturing parameters, each specimen was built in an enclosed environment, with an extrusion temperature of $272^{\circ} \mathrm{C}$ and each layer structure consisting of an external wall built with 2 concentric layers. The unreinforced layers have a $45^{\circ}$ raster angle (measured between the $\mathrm{X}$ axis of the printer and the printing direction for a single path) and a $90^{\circ}$ raster angle between 2 adjacent layers, as depicted in Figure 3.

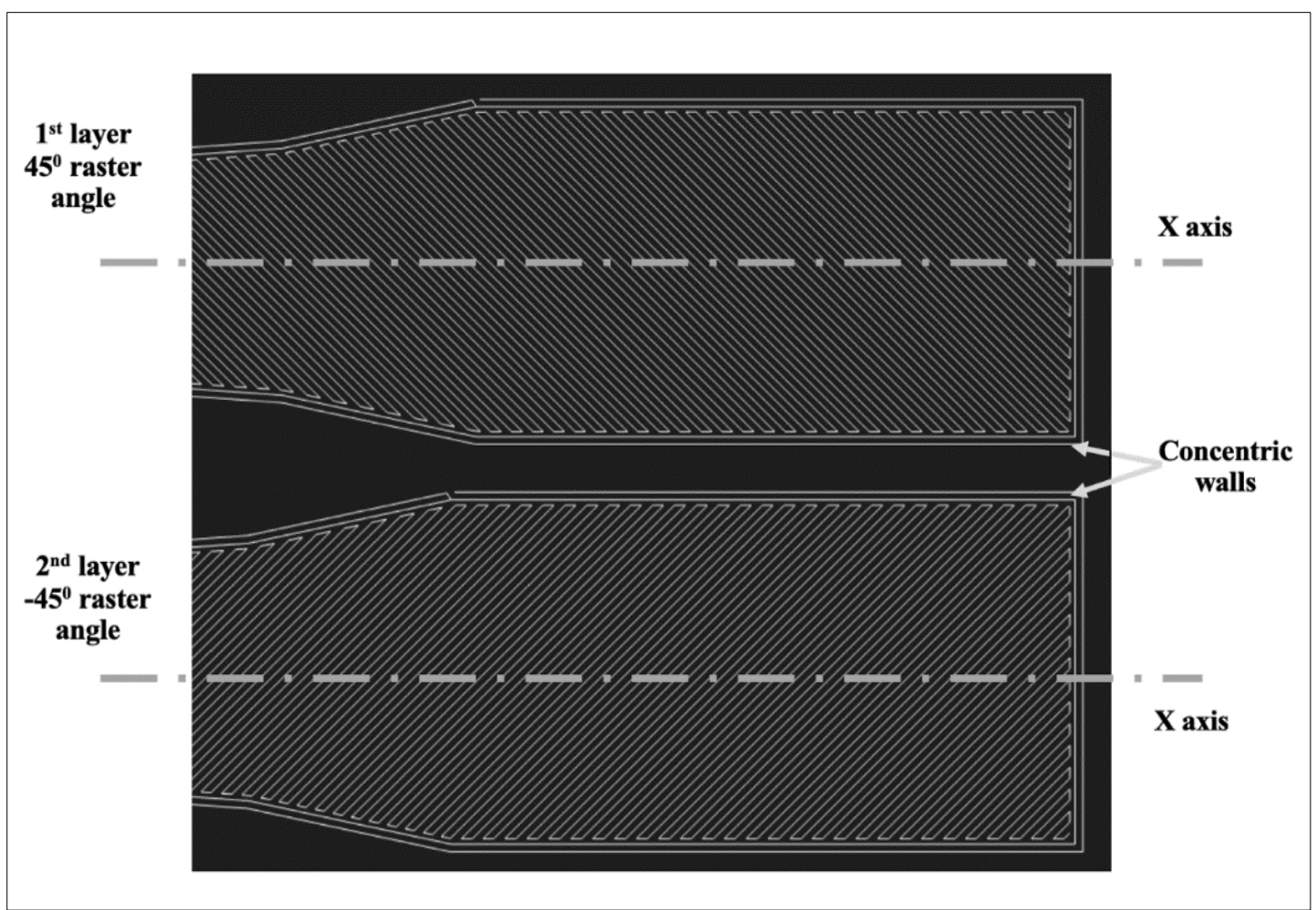

Figure 3. Specimens' unreinforced layer layout 
Reinforcement layers consisted of 8 concentric fiber rings in the widest section of the specimen and 5 concentric rings in the narrow section, with an extra fiber in the middle. The reinforcement fiber is depicted in blue in Figure 4.

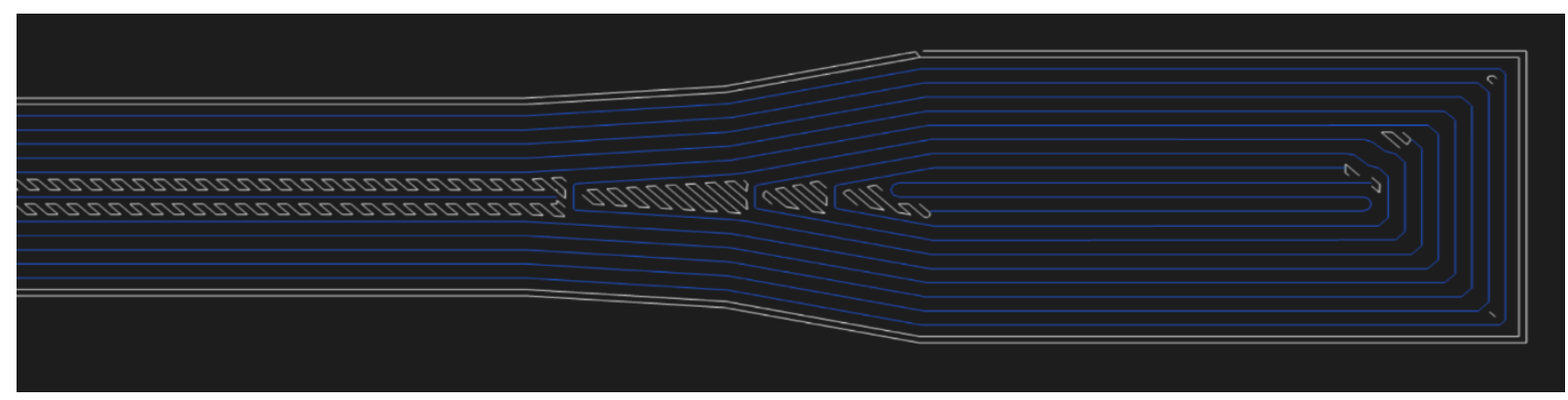

Figure 4. Specimen reinforcement layout

In Table 2 all the major printing parameters are presented.

Table 2. Specimen 3D printing parameters

\begin{tabular}{|c|c|c|c|c|c|}
\hline Specimen type & $\begin{array}{c}\text { Infill } \\
\text { density }\end{array}$ & Raster angle & Side wall no. & $\begin{array}{c}\text { Layer } \\
\text { thickness }\end{array}$ & Reinforcement type \\
\hline Simple & $40 \%$ & $45^{0}$ & 2 & $0.1 \mathrm{~mm}$ & - \\
\hline Glass fibre & $40 \%$ & $45^{0}$ & 2 & $0.1 \mathrm{~mm}$ & $\mathrm{GF}$ \\
\hline Kevlar & $40 \%$ & $45^{0}$ & 2 & $0.1 \mathrm{~mm}$ & $\mathrm{KV}$ \\
\hline Carbon fibre & $40 \%$ & $45^{0}$ & 2 & $0.125 \mathrm{~mm}$ & $\mathrm{CF}$ \\
\hline
\end{tabular}

\subsection{Testing methods}

To determine the mechanical behavior of the specimens manufactured via reinforced and unreinforced $3 \mathrm{D}$ printed materials, the specimens were subjected to uniaxial tensile stress. The Instron 5587 testing machine was used for the uniaxial tension test. The testing machine has a maximum load in a stationary regime of $300 \mathrm{kN}$, an adjustable test speed ranging from 0.001 to $500 \mathrm{~mm} / \mathrm{min}$ and it comes equipped with an 2630-113 series extensometer for measuring the strain in a static regime. The machine is operated via the Bluehill software, which provided automatic sensor calibration, system monitoring, real-time visualization of results and the possibility of determining the conventional stressstrain curves and the true stress - true strain curves.

By coupling the Instron 5587 tensile, compression and buckling testing machine with the Aramis optical measuring system, it was no longer necessary to use an extensometer.

The experimental program for determining the mechanical properties of the specimens manufactured from Onyx and Onyx reinforced with Kevlar fibers, carbon fibers and glass fibers consisted of the following steps:

- sets of three specimens were taken from each type of material. The shape of the test parts was the standard one for this type of test;

- the test speed was set at $5 \mathrm{~mm} / \mathrm{min}$ in order for the test to be carried out in a quasi-static mode;

- the width of the test part was $13 \mathrm{~mm}$ and the calibrated measuring distance was $50 \mathrm{~mm}$;

- before performing the experiments, the specimens were kept in the laboratory at a constant temperature of $25^{\circ} \mathrm{C}$.

- the output data that were collected were the following: the E-modulus [GPa], the maximum tensile stress and the tensile strain at maximum tensile stress. This type of data output was chosen at the expense of the tensile stress and strain at break because the moment when the testing machine detects the fracture is when the traction force suddenly decreases by $10-20 \%$. This is beneficial for metal specimens and laminated composites alike. The reinforced composite material behaves differently in comparison to these types of materials because reinforced fibers can break successively, the force decreasing smoothly 
during the testing process. This makes it impossible to accurately determine the fracture of the specimen and implicitly becomes impossible to determine the tensile stress and strain at break;

- in addition to the above-mentioned data, the primary test data are saved (the characteristic curve in the force $[\mathrm{N}]$ - displacement [mm] coordinates). These data appear as pairs of points in the previously mentioned coordinates in the file of each analysis in ASCII format.

- in order to determine the major strains using digital image correlation, the specimens were preliminarily prepared to this end. The classical method of determining strains via this optical system is that of successively measuring the displacements of some points from the measured area. These points are deposited as fine splashes of graphite or black paint applied over a previously applied matte white paint. The GOM's Aramis system was employed for this purpose because it allows both the acquisition of images and their processing. Two high-resolution lenses with a focal length of $50 \mathrm{~mm}$ were used. Before starting the straining process, the measuring area, a 96x96x40 mm parallelepiped-shaped zone, was calibrated. The measurement technique consisted of taking a picture every second in order to record the moment of the fracture.

By using an optical measurement technique, the user can determine the displacements and the strains only at the external surface of a specimen. This means that only the local strains which are tangential to the surface can be determined. To determine thickness reduction (strain on normal direction), the operation is based on the volume constancy law.

GOM's Aramis, the optical measurement system, allowed us to determine three strain categories: technical strain, logarithmic or true strain and Green's strain. Since the strain is a measure of the deformation of a linear element, in the Aramis software the stretch ratio is a relative elongation of an infinitesimal element [19].

The stretch ratio is calculated as follows:

$$
\lambda=\frac{l}{l_{0}}=\frac{l_{0}+\Delta l}{l_{0}}
$$

Here, $l_{o}$ represents the initial length of the infinitesimal element, $l$ represents the final length of the infinitesimal element and $\Delta 1$ represents the elongation of the infinitesimal element $\left(\Delta l=l-l_{0}\right)$ ).

The technical strain, also called engineering strain or Cauchy strain, is expressed through the following relation:

$$
\varepsilon^{T}=\frac{\Delta l}{l_{0}}=\frac{l-l_{0}}{l_{0}}=\lambda-1
$$

The logarithmic strain, also called true strain or Hencky strain, is expressed via the following relation:

$$
\varepsilon^{L}=\ln \left(\frac{l}{l_{0}}\right)=\ln \left(1+\varepsilon^{T}\right)=\ln (\lambda)
$$

The Green's strain is expressed as follows

$$
\varepsilon^{G}=\frac{1}{2} \cdot\left(\frac{l^{2}-l_{0}^{2}}{l_{0}^{2}}\right)=\frac{1}{2} \cdot\left(\lambda^{2}-1\right)
$$

For the present study, the logarithmic (true) strain was preferred over the other for two main reasons: first, it provides the correct measurement of the final strain when deformation takes place in a series of increments (such as in our case - uniaxial tensile test) and second because it makes it easier to compare future research results obtained via finite element simulation.

\section{Results and discussions}

Figures 5 to 8 show the conventional stress curve along with the tensile stress - tensile strain coordinates for the four cases, while Table 3 illustrates the results of the tensile tests together with the related statistical processing. 


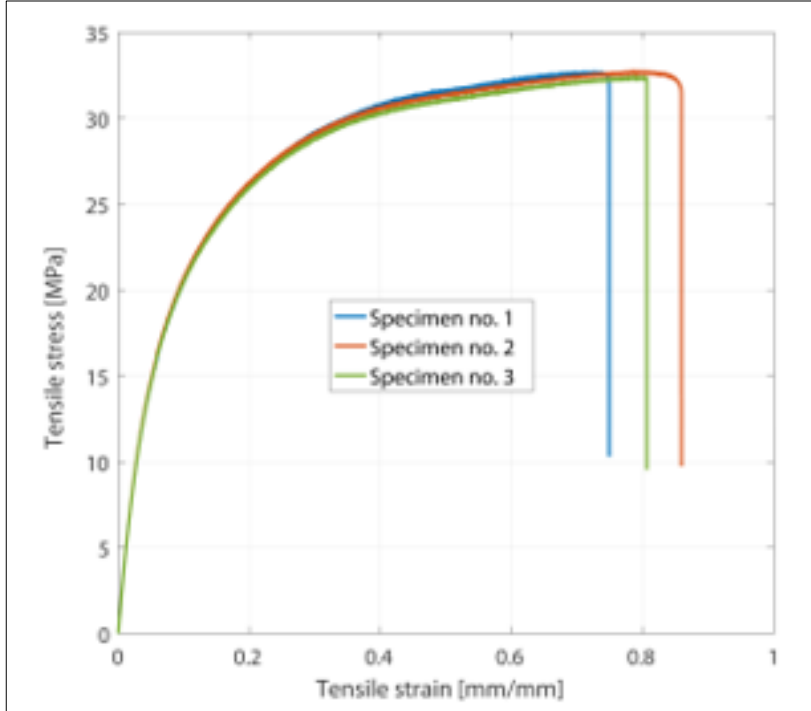

Figure 5. Tensile stress - tensile strain curve for onyx material

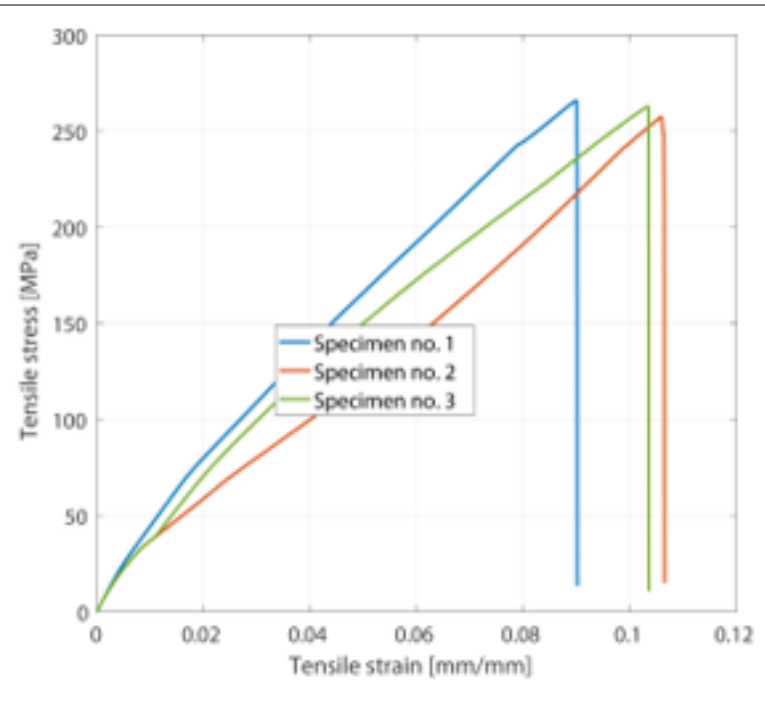

Figure 6. Tensile stress - tensile strain curve for onyx reinforced with Kevlar fibers

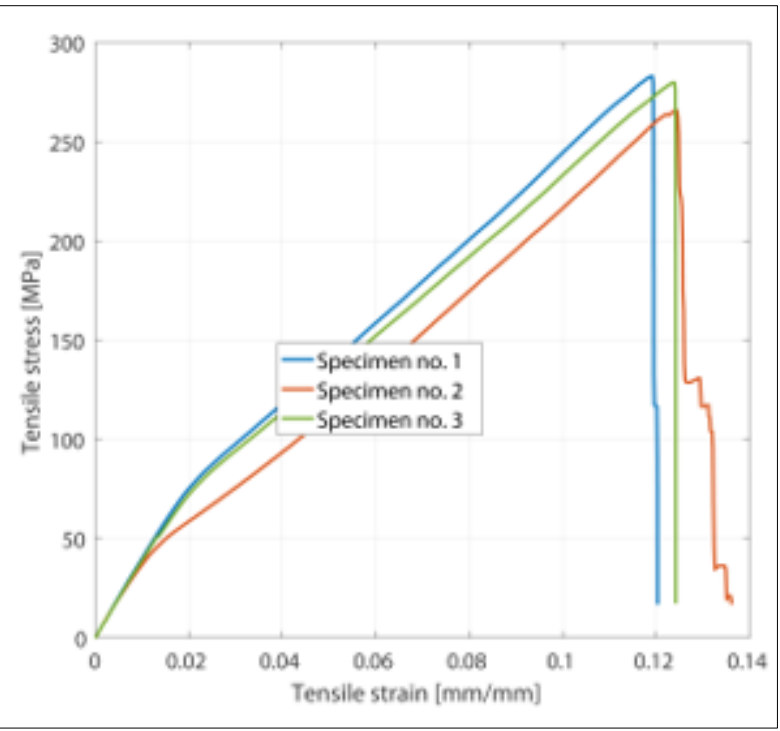

Figure 8. Tensile stress - tensile strain curve for onyx reinforced with glass fibers

Table 3. Mechanical characteristics for onyx

\begin{tabular}{|c|c|c|c|c|c|}
\hline & Statistics & Onyx & $\begin{array}{l}\text { Onyx reinforced with } \\
\text { Kevlar fibers }\end{array}$ & $\begin{array}{l}\text { Onyx reinforced with } \\
\text { glass fibers }\end{array}$ & $\begin{array}{l}\text { Onyx reinforced with } \\
\text { carbon fibers }\end{array}$ \\
\hline \multirow{3}{*}{$\begin{array}{c}\text { Elastic } \\
\text { Modulus } \\
\text { (E modulus) }[\mathrm{GPa}]\end{array}$} & Mean & 0.473 & 4.95 & 4.046 & 7.885 \\
\hline & $\begin{array}{c}\text { Standard } \\
\text { Deviation }\end{array}$ & 0.007 & 0.277 & 0.062 & 0.429 \\
\hline & $\mathrm{p}$-value & 0.498 & 0.125 & 0.329 & 0.096 \\
\hline \multirow{3}{*}{$\begin{array}{l}\text { Maximum Tensile } \\
\text { stress }[\mathrm{MPa}]\end{array}$} & Mean & 32.630 & 261.957 & 276.134 & 290.570 \\
\hline & $\begin{array}{c}\text { Standard } \\
\text { Deviation }\end{array}$ & 0.177 & 4.225 & 9.001 & 3.679 \\
\hline & $\mathrm{p}$-value & 0.172 & 0.514 & 0.225 & 0.164 \\
\hline \multirow{3}{*}{$\begin{array}{l}\text { Tensile strain at } \\
\text { maximum Tensile } \\
\text { stress }[\mathrm{mm} / \mathrm{mm}]\end{array}$} & Mean & 0.759 & 0.099 & 0.122 & 0.080 \\
\hline & $\begin{array}{c}\text { Standard } \\
\text { Deviation }\end{array}$ & 0.029 & 0.008 & 0.003 & 0.002 \\
\hline & $\mathrm{p}$-value & 0.523 & 0.189 & 0.106 & 0.557 \\
\hline
\end{tabular}


The values of the E-modulus, the tensile stress and the tensile strain at maximum tensile stress are shown in the summarizing Table 3. The mean value, the median value, the standard deviation, the coefficient of variation and the p-value were also calculated for each set of experiments. As shown in the table, the Anderson-Darling test was applied to verify the normality of the data distribution. For all four types of specimens, the results prove that the normal data distribution is complied with because the p-value is higher than the minimum value of 0.05 .

Figures 9 to 12 show the results obtained by means of the Aramis optical measuring system for all four cases. The major strain, the minor strain (for Onyx) and the major strain (a.), the minor strain (b.) and the shear angle (c.) for the other three types of materials were measured.
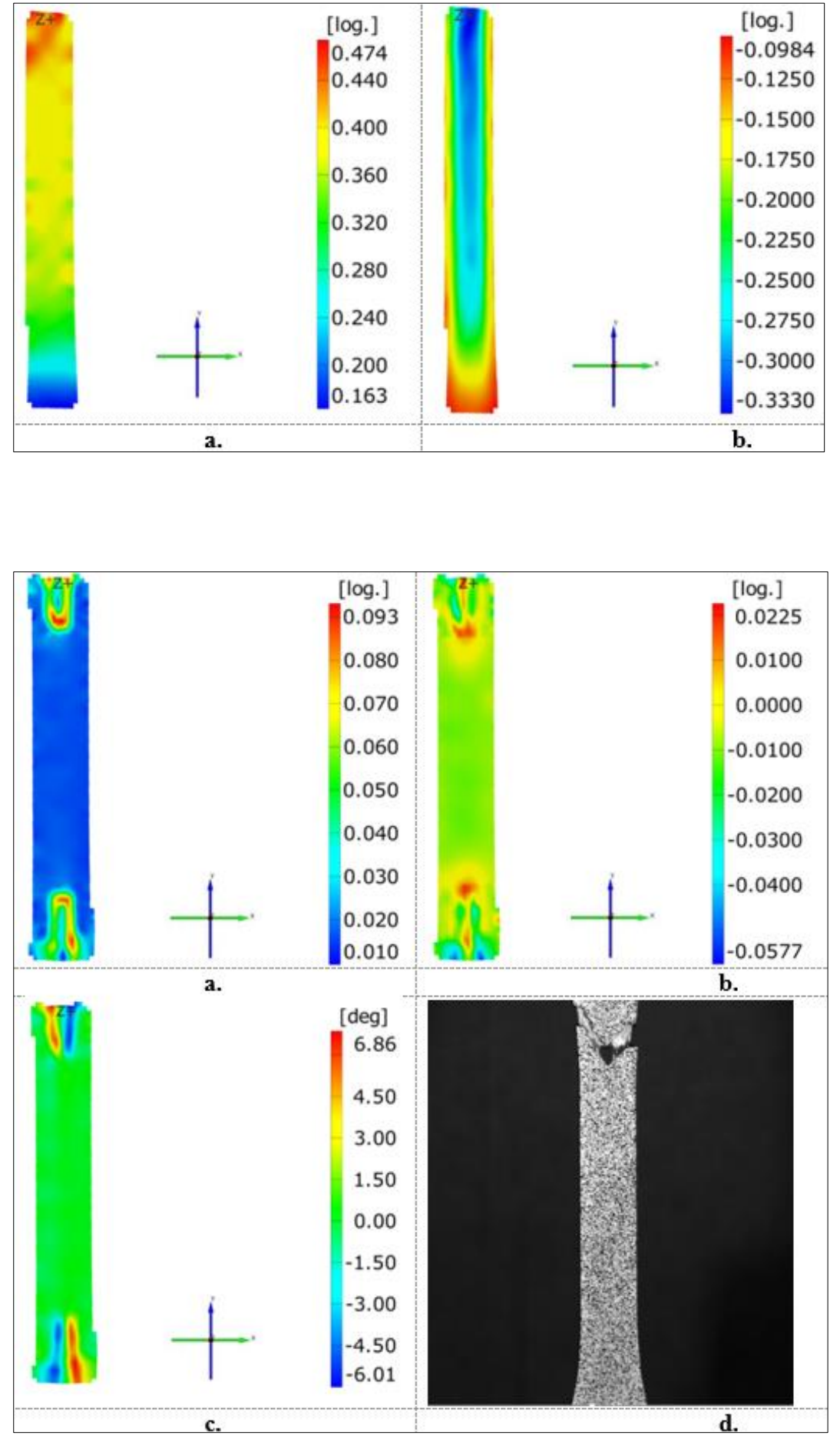

Figure 9. The results for Onyx before fracture. a. Logarithmic major strain map, b. Logarithmic minor strain map
Figure 10. The results for Onyx reinforced with Kevlar fibers before fracture. a. - Logarithmic major strain map, b. Logarithmic minor strain map, c. Shear angle map, d. Specimen fracture 


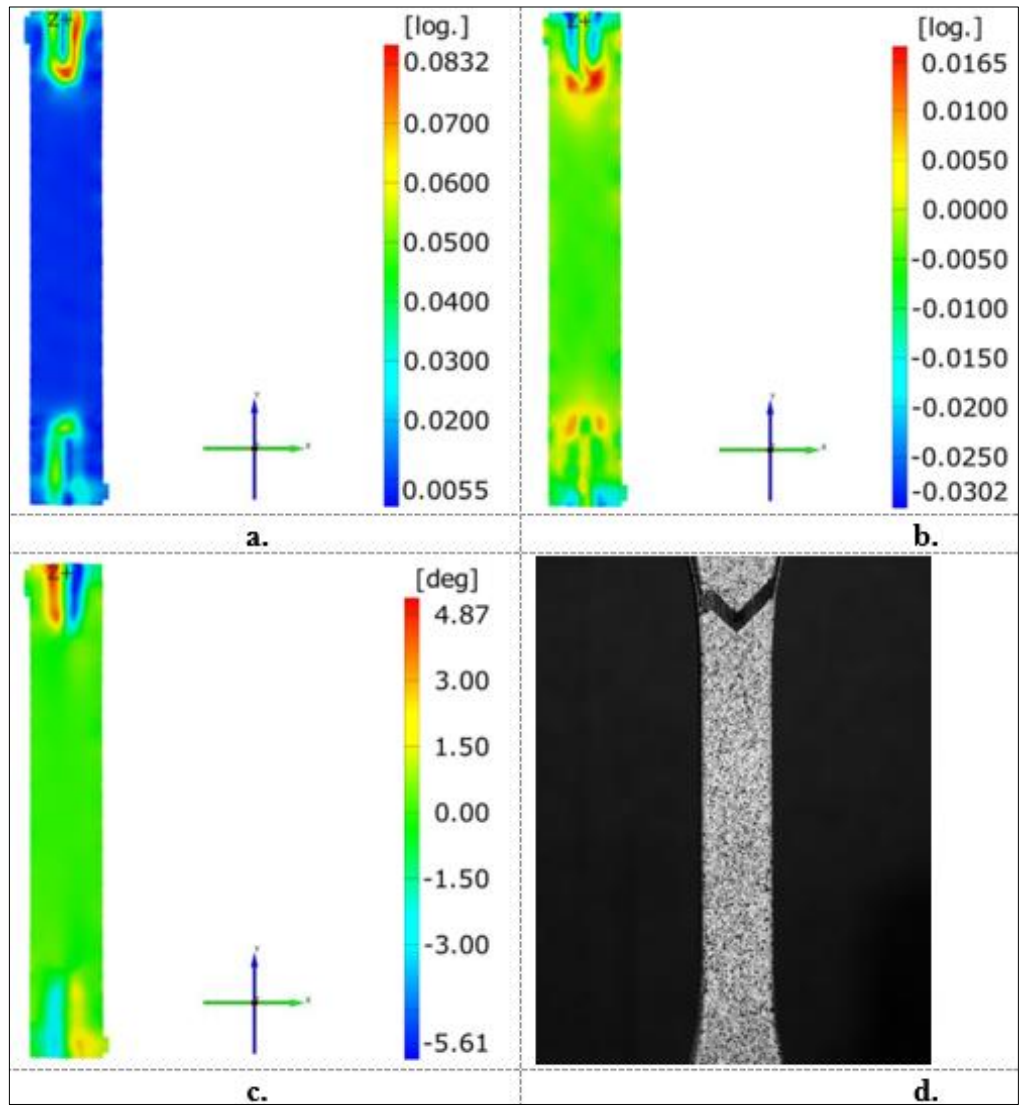

Figure 11. The results for Onyx reinforced with carbon fiber before fracture. a. Logarithmic major strain map, b. Logarithmic minor strain map, c. Shear angle map, d. Specimen fracture

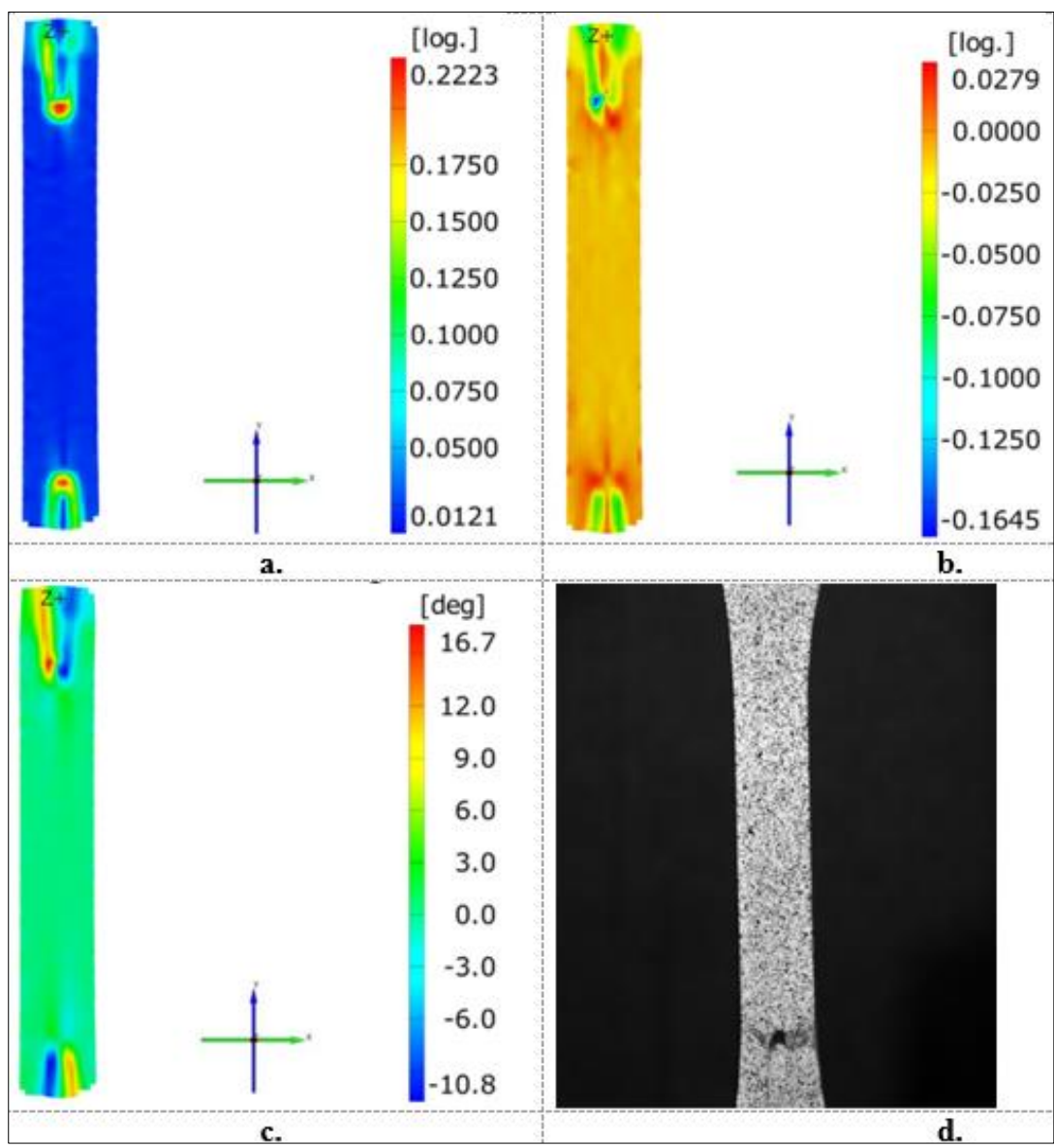

Figure 12. The results for Onyx reinforced with glass fiber before fracture.

a. - Logarithmic major strain map, b. Logarithmic minor strain map, c. Shear angle map, d. Specimen fracture 
By examining the graphs in Figures 5 to 8, it can be easily seen that, in the case of Onyx, the fracture occurs after reaching a level of plastic flow specific to the polymeric materials. The composition of Onyx (a mix of nylon and micro carbon fiber) is responsible for the results in the uniaxial tensile test graph. The analysis of the obtained values led to an average value of $0.473 \mathrm{GPa}$ for the E-modulus, an average value of $32.63 \mathrm{MPa}$ for the maximum tensile test and an average value of $0.759 \mathrm{~mm} / \mathrm{mm}$ for the tensile strain at maximum tensile stress.

The average values for E-modulus, maximum tensile stress, and tensile strain at the maximum tensile stress for all four types of materials tested are shown in table 3.

The materials containing Onyx that were reinforced with various other materials and subjected to tests for the present paper (Table 3) demonstrated in all cases a much higher fracture strength than Onyx, exceeding it by over $800 \%$ in the case of all three reinforcement materials (Onyx with Kevlar $802.81 \%$, Onyx with glass fiber $846.26 \%$ and Onyx with carbon fiber $890.50 \%$ ). This increase in the maximum strength comes, however, with a decrease in fracture strain. Thus, in the case of this mechanical property, decreases of over 10\% were recorded (Onyx with Kevlar fibers $13.04 \%$, Onyx with glass fibers $16.07 \%$ and Onyx with carbon fibers $10.54 \%$ ).

As for the Elastic modulus, it can be noted that, for all the reinforced materials, a significant increase of this elastic parameter was observed (Onyx with Kevlar fibers 10.47\%, Onyx with glass fibers $8.55 \%$ and Onyx with carbon fibers $16.67 \%$ ).

The analysis of the images obtained with the Aramis optical analyzer indicated that, in the case of the reinforced specimens, the fracture occurs in the area where the 5 concentric rings in the narrow section of the specimen end and the 8 concentric fiber rings in the widest section begin. The distribution of the major and minor strain follows this pattern, too.

The stress increases since part of the load are taken from the reinforcing fibers.

A ductile fracture was recorded in the reinforcement area, with the fracture being brittle in the area where there is no reinforcement.

It can be noted that for the specimens built with unreinforced Onyx, the distribution of the major strain and the minor strain is even along the calibrated length of the specimen, increasing the value locally only before the fracture occurs. The maximum value of the major strain is found near the mobile crosshead where the fracture also occurs and has a maximum value of $0.474 \mathrm{~mm} / \mathrm{mm}$. The maximum value of the minor strain in the module is $0.33 \mathrm{~mm} / \mathrm{mm}$. Due to the increased homogeneity of the material compared to the reinforced specimens, no specific deformations which could be associated with the shear angle were found in the specimens manufactured based on Onyx without reinforcements.

In the specimens reinforced with carbon fiber, glass fiber and Kevlar, both the major strain and the minor strain have a relatively symmetrical distribution both on the direction of the load and the $\mathrm{X}$ axis. The shear angles are present in the area in which the fracture occurs, leading to a "V" fracture of the test specimen. The maximum values of the major strain and minor strain are present in the area where the reinforcement is missing.

Table 4. The maximum value of the major strain, minor strain and shear angle

\begin{tabular}{|c|c|c|c|}
\hline $\begin{array}{c}\text { Maximum } \\
\text { values }\end{array}$ & $\begin{array}{c}\text { Onyx reinforced with } \\
\text { carbon fibers }\end{array}$ & $\begin{array}{c}\text { Onyx reinforced with } \\
\text { glass fibers }\end{array}$ & $\begin{array}{c}\text { Onyx reinforced with } \\
\text { Kevlar fibers }\end{array}$ \\
\hline $\begin{array}{c}\text { The major strain } \\
{[\mathrm{mm} / \mathrm{mm}]}\end{array}$ & 0.083 & 0.222 & 0.093 \\
\hline $\begin{array}{c}\text { The minor strain } \\
{[\mathrm{mm} / \mathrm{mm}]}\end{array}$ & 0.016 & 0.16 & 0.025 \\
\hline $\begin{array}{c}\text { The shear angle } \\
\text { [degree] }\end{array}$ & 5.61 & 16.7 & 6.86 \\
\hline
\end{tabular}

Table 4 displays the maximum value of the major strain, the maximum value of the minor strain and the maximum value of the shear angle for each type of reinforcement. These values were recorded for the area in which the specimen fractures. 


\section{Conclusions}

It is widely known that the specimens manufactured by 3D printing Onyx, a new generation material, which also contains ground/crushed carbon fibers, exhibit much-improved fracture strength compared to the unreinforced polymeric materials which are commonly used in additive manufacturing, such as PLA, PP, ABS, etc.

It can be concluded that the existence of reinforcement leads in all cases to an increase in the rigidity of the reinforced specimens, the most important increase being noted in the case of the Onyx specimens reinforced with carbon fiber, followed by the Onyx specimens reinforced with glass fiber and lastly by those reinforced with Kevlar.

Moreover, it can be seen that the materials reinforced with different types of fibers display an increase in mechanical strength and higher elasticity, due to the phenomenon of taking over by the loadreinforcing fiber to which the specimen is subjected.

As far as the rate of the characteristic curves is concerned, a major change can be observed in the performance of reinforced materials relative to specimens manufactured exclusively from Onyx; specifically, in reinforced materials, the tensile stress increases at a steady pace during the test until the maximum value is reached (of course, at different rates for each of the three types of reinforcements).

All these findings confirm the fact that these materials can be part of a new generation of materials with higher fracture strength which could be used more frequently in the additive manufacturing of various components.

\section{References}

1.ABOURAYANA, H.M., DOBBYN, P.J., DOWLING, D.P., Enhancing the mechanical performance of additive manufactured polymer components using atmospheric plasma pre-treatments. Plasma Process Polym. 2018.

2.BÁRNIK, F., VAŠKO, M., HANDRIK, M., DORC`IAK, F., MAJKO, J., Comparing mechanical properties of composites structures on Onyx base with different density and shape of fill. Transp. Res. Procedia 2019, 40, 616-622.

3.JONES, R. M., Mechanics of Composite Materials Second Edition, ISBN: 1-56032-712-X Philadelphia, 1999.

4. BETTINI, P., ALITTA, G., SALA, G., LANDRO, L.D., Fused Deposition Technique for Continuous Fiber Reinforced Thermoplastic. J. Mater. Eng. Perform. 2016, 26, 1-6.

5.NGO, T.D., KASHANI, A., IMBALZANO, G., NGUYEN, K.T., HUI, D., Additive manufacturing (3D printing): A review of materials, methods, applications and challenges. Compos. Part B Eng. 2018, $143,172-196$.

6.XING H., ZOU B., LIU X., WANG X., HUANG C, HU Y., Fabrication strategy of complicated $\mathrm{Al}_{2} \mathrm{O}_{3}{ }^{-}$ $\mathrm{Si}_{3} \mathrm{~N}_{4}$ functionally graded materials by stereolithography 3D printing. J Eur Ceram Soc 2020. https://doi.org/10.1016/j.jeurceramsoc.2020.05.022

7.WANG P., ZOU B., DING S., LI L., HUANG C., Effects of FDM-3D printing parameters on mechanical properties and microstructure of CF/PEEK and GF/PEEK. Chin J Aeronaut 2020.

8.XING H., ZOU B., LIU X., WANG X., CHEN Q., FU X., et al. Effect of particle size distribution on the preparation of ZTA ceramic paste applying for stereolithography 3D printing. Powder Technol 2020; 359:314-22. https://doi.org/10.1016/j. powtec.2019.09.066.

9.WANG, P., ZOU, B., DING, S., HUNAG, C., SHI, Z., MA, Y., YAO, P., Preparation of short CF/GF reinforced PEEK composite filaments and their comprehensive properties evaluation for FDM-3D printing. Compos. Part B 2020, 198, 108175.

$10 . * * * 3 \mathrm{D}$ Printer Manufacturer \& Technology Company

https://static.markforged.com/downloads/CompositesDesignGuide.pdf (accessed on 21 June 2021).

11.FU, S.-Y., LAUKE, B., MÄDER, E., YUE, C.-Y., HU, X., Tensile properties of short-glass-fiberand short-carbon-fiber-reinforced polypropylene composites. Compos. Part A 2000, 31, 1117-1125.

12.YU, S., HWANG, Y.H., HWANG, J.Y., HONG, S.H., Analytical study on the 3D-printed structure 
and mechanical properties of basalt fiber-reinforced PLA composites using X-ray microscopy. Compos. Sci. Technol. 2019, 175, 18-27.

13.ZHONG, W., LI, F., ZHANG, Z., SONG, L., LI, Z., Short fiber reinforced composites for fused deposition modeling. Mater. Sci. Eng. 2001, 301, 125-130.

14.SODEIFIAN, G., GHASEMINEJAD, S., YOUSEfi, A.A., Preparation of polypropylene/short glass fiber composite as Fused Deposition Modeling (FDM) filament. Results Phys. 2019, 12, 205-222.

15.TIAN, X., LIU, T., YANG, C., WANG, Q., LI, D., Interface and performance of 3D printed continuous carbon fiber reinforced PLA composites. Compos. Part A Appl. Sci. Manuf. 2016, 88, 198205.

16.YANG, C., TIAN, X., LIU, T., CAO, Y., LI, D., 3D printing for continuous fiber reinforced thermoplastic composites: Mechanism and performance. Rapid Prototyp. J. 2017, 23, 209-215.

17.MATSUZAKI, R., UEDA, M., NAMIKI, M., JEONG, T.K., ASAHARA, H., Three-dimensional printing of continuous-fiber composites by in-nozzle impregnation. Sci. Rep. 2016, 6, 23058.

18. *** ASTM International, "D638-02a Standard Test Method for Tensile Properties of Plastics," 2003

19. *** Aramis User Manual - Software, GOM mbH, 2007

Manuscript received: 23.07.2021 